\title{
Papilloedema in association with Hunter's syndrome
}

\author{
MARILYN BECK \\ From University Hospital of Wales, Heath, Cardiff CF4 4XN
}

SUMmARY A 34-year-old man with Hunter's syndrome is described. He has been known to have gross bilateral papilloedema for 11 years but still retains good visual acuity.

Hunter's syndrome was first described in $1917^{1}$ and is due to a disorder of mucopolysaccharide metabolism, usually inherited as an $\mathrm{X}$-linked recessive trait. Affected individuals lack the enzyme L-iduronate sulphatase responsible for degrading acid mucopolysaccharides and thus store large amounts of these mucopolysaccharides in their tissues. McKusick ${ }^{2}$ in his classification of the mucopolysaccharidoses designated this syndrome as type 11 . This type may be subdivided into grade A (severe) and B (mild) depending on the intellectual impairment and longevity. Survival has been reported up to the sixth decade $^{2}$ with minimal or absent intellectual impairment in the mild form.

The syndrome is characterised by short stature, large head with coarse gargoyle features, hirsutism, deafness, joint stiffness and skeletal deformities, heart abnormalities, hepatosplenomegaly, protuberant abdomen and an umbilical hernia. Various degrees of intellectual impairment occur. The ocular findings described are exophthalmos, hypertelorism, clear corneae (in contrast to Hurler's syndrome), papilloedema, and a pigmentary retinopathy.

The case described is the oldest surviving individual with Hunter's syndrome in the United Kingdom. ${ }^{3}$

\section{Case history}

The patient, now aged 34 years (Figs. $1 \mathrm{~A}, \mathrm{~B}),{ }^{*}$ presented at the age of 4 years with deafness and joint stiffness. Gargoylism was diagnosed because of his short stature, facial appearance, protuberant abdomen with hepatosplenomegaly, and an umbilical hernia. At the age of 12 years he began to suffer from recurrent chest infections, and when he was aged 25 he had an episode of heart failure secondary to his mixed aortic valve disease. Over the last few years his

Correspondence to Mrs M. Beck. FRCS. University Hospital of Wales. Heath Park. Cardiff CF4 4XW. joint problems have increased, and his main complaint at present is of severe hip pain which makes his job as a van driver difficult.

His male cousin, who also had Hunter's syndrome, died aged 20 years due to upper airways obstruction after dental surgery. ${ }^{4}$

The patient was first examined by an ophthalmologist in July 1971 (aged 23 years), as he complained of intermittent blurring of vision. On examination his visual acuities were $6 / 6$ right, $6 / 6$ left, with a strong hypermetropic correction. Slit-lamp examination showed normal anterior segments with clear corneae, and the intraocular pressures were normal. Fundal examination was recorded as showing bilateral disc blurring but normal peripheral fundi. Visual fields were charted on a Goldmann perimeter and were normal apart from bilateral enlargement of the blind spots.

In 1972 he was found to have gross bilateral papilloedema, normal vessels, and normal peripheral fundi. In 1973 a fluorescein angiogram (Fig. 2) confirmed that this was true papilloedema. A lumbar puncture performed in that year showed normal cerebrospinal fluid pressures (opening at $180 \mathrm{~mm} \mathrm{CSF}$ and falling to $140 \mathrm{~mm} \mathrm{CSF}$ ). A myelogram showed an almost complete block at the C7-T1 level.

As his visual obstructions became more frequent in 1973, he was given a course of plasma infusion therapy (at 3-monthly intervals over 2 years), and isosorbide, an osmotic agent, was also tried. The latter was discontinued owing to difficulty in getting supplies. Despite the fact that his disc appearances remained unchanged, his visual symptoms improved.

He was followed up at 6-monthly intervals and in 1980 was noted to have early pigmentary retinal changes in the left fundus. An electroretinogram performed in 1981 showed markedly decreased $b$ waves bilaterally. 


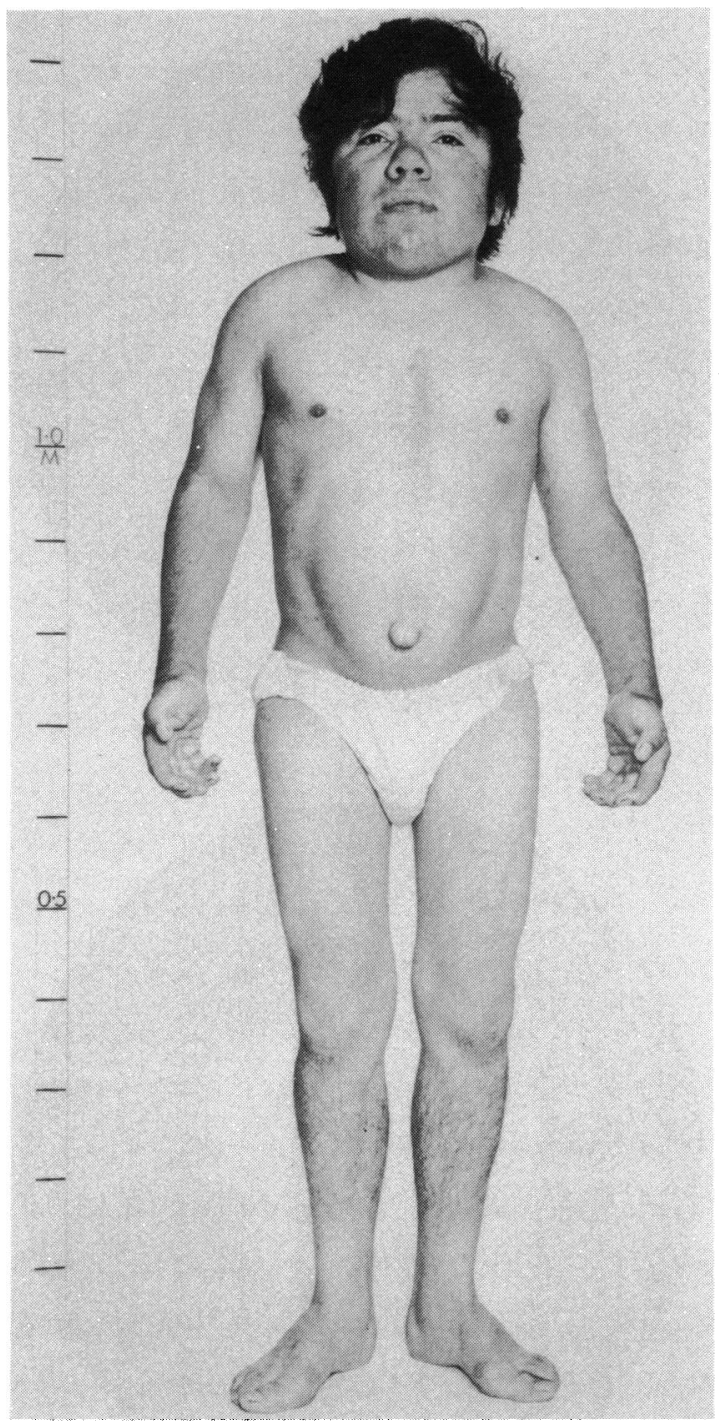

Fig. 1A Photograph of patient showing his short stature, claw hands, and umbilical hernia.

When he was last seen in March 1982 he complained of increasing difficulty in seeing at night. On examination his visual acuities were still $6 / 6$ right and left with glasses. Slit-lamp examination showed clear corneae. Funduscopy showed no detectable change in the gross papilloedema, but there was an increase in the pigmentary retinal changes in the central area of each fundus. The visual fields remained full peripherally, but there were scotomata centrally corresponding to the areas of retinal change. Skull $x$-rays showed no signs of increased intracranial pressure, and the optic foramina were of normal size. A CT scan showed symmetrical ventricles with no

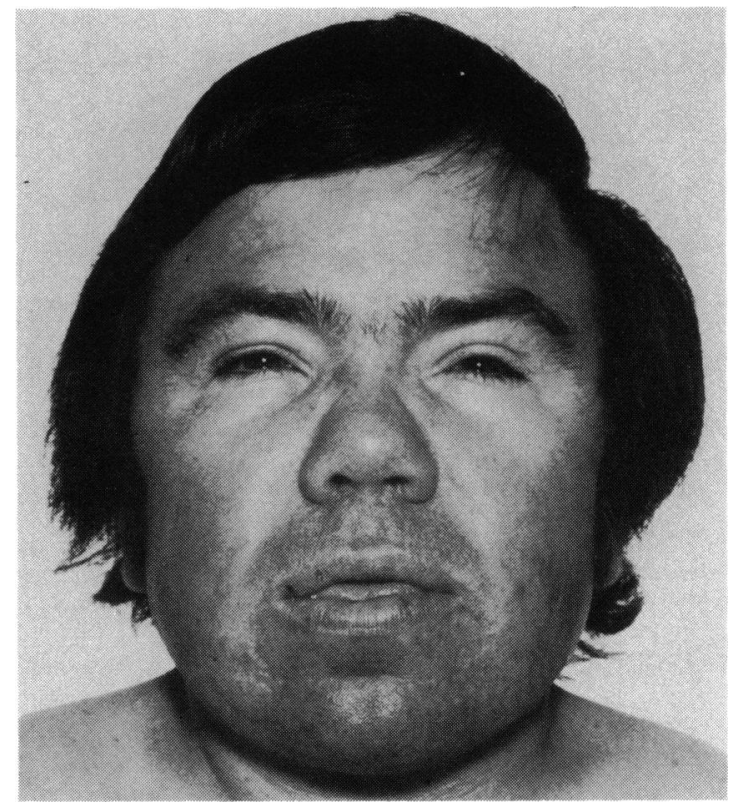

Fig. 1B Facial appearance of patient showing coarse gargoyle features.

areas of abnormal density and no identifiable cause for the papilloedema. Fluorescein angiography again confirmed the presence of papilloedema (Figs. 3A, B, C).

*The patient died on 25 September 1982 of respiratory failure following hip surgery.

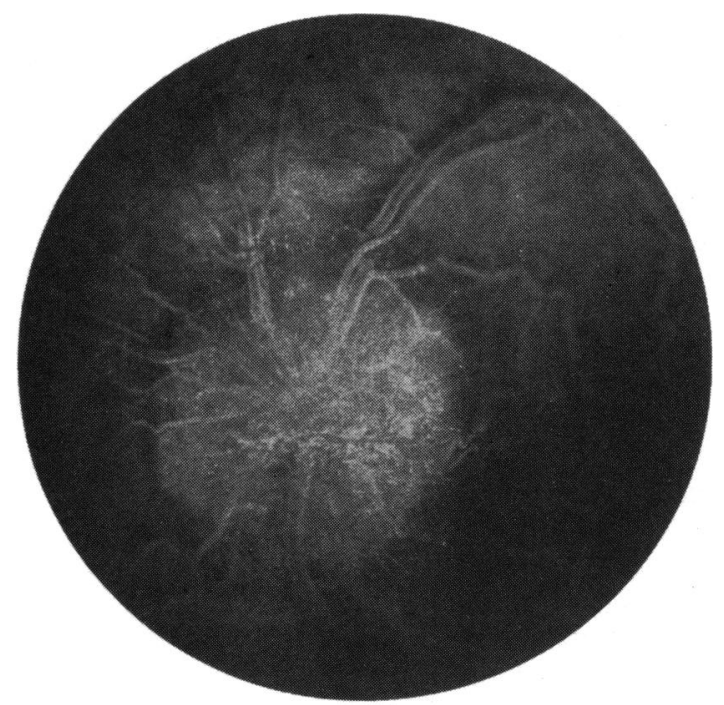

Fig. 2 Left fluorescein angiogram (1973) showing dilatation of the prepapillary capillaries in the early transit phase. 


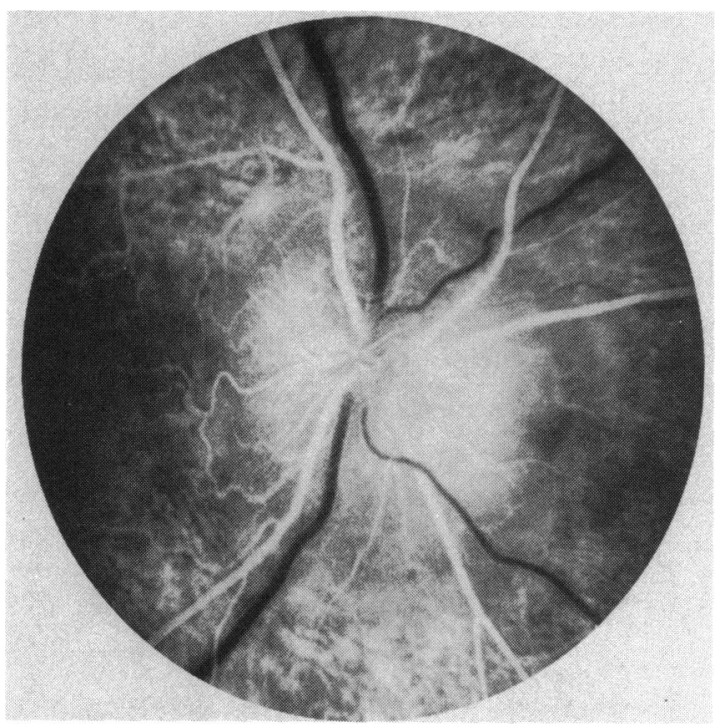

Fig. 3A

Fig. 3 Fluorescein angiograms (1982) showing (A) dilatation of the prepapillary capillary plexus of the right disc during the early transit phase, (B) hyperfluorescence of the right disc at 5 minutes post injection, and $(\mathrm{C})$ hyperfluorescence of the left disc.

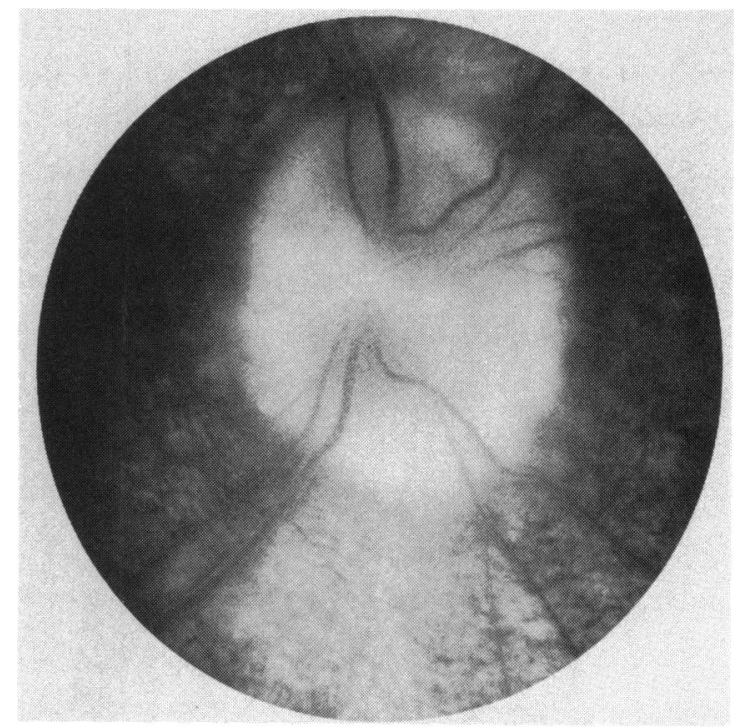

Fig. 3B

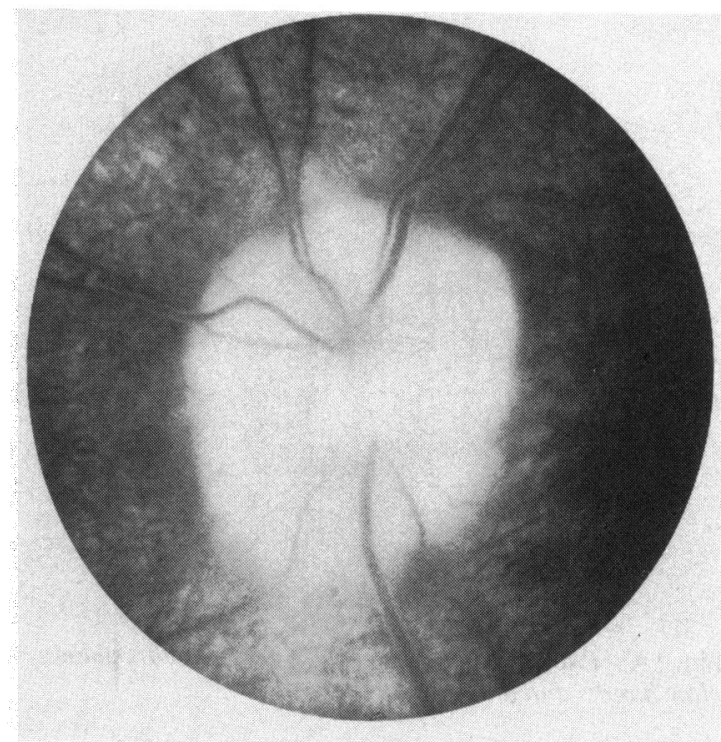

Fig. 3C

2 patients with Hunter's syndrome in whom mild corneal changes were noted. Gills et al. ${ }^{5}$ described a patient who was found at the age of 33 years to have a slight haziness of the posterior corneal stroma. A 25-year-old patient was reported by Spranger ${ }^{6}$ to have fine corneal opacities visible on slit-lamp examination. Histologically, abnormal mucopolysaccharides have been found deposited in the periphery of the corneae of a patient with Hunter's syndrome $^{78}$ despite the fact that these corneae 
seemed clear during life. At the age of 34 this patient's corneae still remained clear biomicroscopically.

Pigmentary retinal changes indistinguishable from retinitis pigmentosa have been described in this syndrome. ${ }^{59}$ They were also found in the eyes examined histologically by Goldberg and Duke ${ }^{7}$ and Topping et al. ${ }^{8}$

In our case the patient had nyctalopia at the age of 32 years and subsequently developed a pigmentary retinopathy. His electroretinogram was found to be markedly subnormal, and similar electroretinographic findings in patients with Hunter's syndrome have been described. ${ }^{510}$ McKusick $^{2}$ states that 'the oldest survivors of the kindred reported by Beebe and Formel $^{11}$ were blind as a result of retinal changes.' Retinopathy occurs in other forms of mucopolysaccharidoses (types $1 \mathrm{H}, 1 \mathrm{~S}$, and 111) but is obviously more difficult to detect in the presence of corneal clouding.

Papilloedema, blurring of the disc margins, and optic atrophy ${ }^{2}$ have all been described in association with Hunter's syndrome. McKusick ${ }^{2}$ described 2 patients with papilloedema. The first patient had had papilloedema for 10 years and was found to have cerebral atrophy and internal hydrocephalus at autopsy. The second case died after an attempt to relieve the hydrocephalus and papilloedema by choroidal plexotomy.

The aetiology of the florid papilloedema in this present case is, however, obscure. Fluorescein angiography performed in 1973 and 1982 confirmed that this is true papilloedema. Skull $x$-rays show no signs suggesting chronic raised intracranial pressure, and no ventricular dilatation or intracranial mass was shown by CT scan. The cerebrospinal fluid pressure was normal at lumbar puncture. Although this could have been a spurious result because a lower cervical block was demonstrated on myelography, there is no convincing evidence for raised intracranial pressure as the cause of papilloedema in this patient.

The disc appearances could possibly be due to infiltration of the optic nerves with mucopolysaccharides. Peripheral nerve infiltration with mucopolysaccharides has been described in Hunter's syndrome, ${ }^{12}$ and McKusick $^{2}$ has reported enlargement of the optic foramina in association with Hurler's syndrome. However, no enlargement of the optic foramina was detected radiographically in this patient, and the optic nerves appeared to be of normal size on CT scan. The only histological reports on the eyes of a patient with Hunter's syndrome and by Goldberg and Duke ${ }^{7}$ and subsequently by Topping et al. ${ }^{8}$ using the electron microscope state that the optic nerves were normal. This patient, however, did not have papilloedema during life.

Despite the ominous appearance of the optic discs, the papilloedema pursued a benign course and was not influenced by plasma infusion therapy or osmotic diuretics. The patient retained good corrected visual acuities over the past 11 years. Until recently, when he began to develop pigmentary retinal changes, his visual fields were normal apart from enlarged blind spots.

It was considered that his papilloedema, despite its sinister appearance, was in the long term less likely to cause visual impairment than the pigmentary retinopathy. However, the patient had multiple systemic disorders, which reduce life expectancy. ${ }^{13}$

Thanks are due to Professor P. Harper and Mr P. V. Mills for permission to study this case and to Mrs S. Campbell for typing the manuscript.

\section{References}

1 Hunter C. A rare disease in two brothers. Proc $R$ Soc Med 1917; 10: 104-16.

2 McKusick VA. The mucopolysaccharidoses. Heritable diseases of connective tissue. 4th ed. St Louis: Mosby. 1972.

3 Young ID. MD thesis. London University, 1981

4 Hopkins R. Watson JA. Jones JH. Walker M. Two cases of Hunter's syndrome. The anaesthetic and operative difficulties in oral surgery. Br J Oral Surg 1973; 10: 286-99.

5 Gills JP. Hopson R. Hanley WB. McKusick VA. Electroretinographic and fundus oculi findings in Hurler's disease and allied mycopolysaccharidoses. Arch Ophthalmol 1965; 74: 596-603.

6 Spranger J. Mucopolysaccharidosis II with corneal opacities. Eur J Pediatr 1978; 129: 11-6.

7 Goldberg MF. Duke JR. Ocular histopathology in Hunter's syndrome. Systemic mucopolysaccharidosis type II. Arch Ophthalmol 1967; 77: 503-12.

8 Topping TM. Kenyon KR. Goldberg MF. Maumenee AE. Ultrastructural ocular pathology in Hunter's syndrome. Systemic mucopolysaccharidosis type II. Arch Ophthalmol 1971; 86: 164-77.

9 Hooper JMD. An unusual case of gargoylism. Guy's Hosp Rep 1952: 101: 222-8.

10 Abraham FA. Yatsiv S. Russell A. Auerbach E. Electrophysiological and psychophysical findings in Hunter's syndrome. Arch Ophthalmol 1974; 91: 181-6.

11 Beebe RT. Formel PF. Gargoylism: sex-linked transmission in nine males. Trans Am Clin Climatol Assoc 1954; 66: 199-207.

12 Swift TR. McDonald DF. Peripheral nerve involvement in Hunter's syndrome (mucopolysaccharidosis II). Arch Neurol 1976: 33: 845-6.

13 Young ID. Harper PS. Long term complications in Hunter's syndrome. Clin Genet 1979; 16: 125-32. 